\title{
Principles of Editorial Policy \\ of the Journal of Asian Studies
}

I. The Journal will consider for publication articles which represent the discipline and area interests of the membership of the Association for Asian Studies, including all subjects in the humanities and social sciences on East Asia, Central Asia, Southeast Asia, and South Asia.

2. The approach in the articles should be descriptive, analytical, or interpretive rather than politically partisan and polemical. Articles should be of a scholarly nature, the fruits of careful research, thought, and analysis, and should be presented in acceptable literary form. More specifically they should (a) present new and significant materials or translations; or (b) provide new or thought-provoking analyses or interpretations supported by sound evidence; or (c) present in English the results of significant foreign scholarship which otherwise would not be readily available; or (d) present material of immediate professional interest, such as bibliographical material or other aids to research.

3. Special consideration will be given to contributions of high quality submitted by younger scholars.

4. In the allocation of space, the Editors will take into consideration the various disciplines and areas of interest of the Association, dependent upon the submission of acceptable manuscripts.

5. Contributions should follow the Journal of Asian Studies Style Sheet, copies of which may be obtained from the Editors.*

6. Contributions in which extensive editorial changes are made will be returned to the authors for approval, but minor editorial and stylistic changes will be made at the discretion of the Editors.

7. As a general rule, articles and other items will be published in the order of their acceptance, but the Editors have discretion to make necessary adjustments.

8. Articles will be accepted or rejected by the Editor after consultation with other Editors or members of the Advisory Editorial Board.

9. Chinese, Japanese, Indic, and other scripts, symbols, etc., will be provided if possible when necessary to present or explain material, but their excessive use should be avoided. Similarly, illustrations, maps, charts, graphs, tables, etc., must be kept to a minimum and will be included at the discretion of the Editors.

ro. Efforts will be made to review, abstract, or translate significant works, articles, and documents published in Asian or less well-known European languages.

II. Review articles and critical reviews of significant scholarly or interpretive books will be featured in the "Book Reviews." Other works will be given briefer notice.

I2. The "Bibliography" will provide as complete coverage of publications in Western languages as possible.

13. Communications or notes concerning articles and reviews which have appeared in the Journal will be considered for publication. The Editors reserve the right to accept, reject, or edit communications in the interests of the membership as a whole. Such contributions should deal with points of substance, and should preferably be self-contained essays on broad issues.

- The JAS Style Sheet is reproduced in its current edition below. 
Under present arrangements, the authors of articles will be provided with fifty free offprints; reviewers and other contributors will be sent two tearsheets.

Reviewers of books for the JAS are routinely provided with a printed "Guide to Reviewers," copies of which are obtainable from the Review Editor, and which outlines a policy and suggested forms for reviews, review articles, and short notices.

In a departure from previous practice, the Editorial Board at its meeting in March agreed that the Editor shall withhold from referees the identity of authors of all manuscripts. Contributors are accordingly requested to omit their names from manuscripts, and to identify themselves to the Editor, giving address as well as name, only in the usual covering letter. 